\title{
Prevalência de injúrias em tecidos moles em pacientes atendidos em um centro especializado no tratamento de traumatismos dentários
}

\author{
Prevalence of soft tissue injuries in patients assisted in a specialized \\ treatment center for dental trauma
}

\author{
Andressa Priebe Figueiró \\ Larissa Tavares Henzel" \\ Renata Uliana Posser \\ Marcelo Pereira da Silva* \\ Tainá Santos da Rosa* \\ Vanessa Polina Pereira Costa*
}

\section{Resumo}

Objetivo: avaliar a prevalência de lesões de tecidos moles em crianças que sofreram traumatismo alveolodentário na dentição decídua, atendidas em um serviço especializado da Faculdade de Odontologia da Universidade Federal de Pelotas. Métodos: os dados coletados dos prontuários dos pacientes atendidos de 2002 a 2011 foram: idade, sexo, injúria em tecidos moles e severidade do traumatismo. Os dados foram analisados por meio de estatística descritiva e associações foram feitas pelo Teste Qui-Quadrado, utilizando o programa Stata 11.0. Resultados: dos 707 prontuários analisados, 603 crianças foram incluídas no estudo. Desse total, 51,41\% apresentaram lesões em tecidos moles, além das injúrias dentárias. A maior prevalência de lesões em tecidos moles foi em crianças de 25 a 36 meses $(24,71 \%)$ e entre o sexo masculino $(58,87 \%)$. A presença de lesões em tecidos moles foi estatisticamente significante em relação à severidade do traumatismo $(p \leq 0,001)$ e à idade da criança $(p=0,004)$, no entanto, não foi observada diferença em relação ao sexo. A lesão em tecido mole mais prevalente foi a laceração, tanto na região extraoral $(46,75 \%)$ quanto na intraoral $(64,10 \%)$, seguida por contusão e abrasão. Considerando todos os tipos de lesões, a região intraoral foi a mais atingida (50,32\%). Conclusão: as lesões em tecido mole estão presentes em grande parte das crianças que sofrem traumatismo (51,41\%), portanto, é necessário ressaltar a importância do exame e do tratamento dessas lesões.

Palavras-chave: Criança. Lesões dos tecidos moles. Prevalência. Traumatismos dentários.

\section{Introdução}

Os traumatismos alveolodentários na dentição decídua são eventos comuns que podem acometer os tecidos duros do dente, os tecidos de sustentação e também os tecidos moles adjacentes. Os traumatismos alveolodentários apresentam uma alta prevalência na dentição decídua, podendo variar de $10 \%$ a $35 \% \%^{1,2}$ e acometendo, normalmente, crianças entre 2 e 4 anos de idade $^{3}$. A prevalência de lesões em tecidos moles relatada na literatura também é alta, $56,2 \%{ }^{4}$, e o tipo mais comum é a laceração $(58,5 \%)$, seguida da contusão $(31,7 \%)$ e da abrasão $(9,8 \%)^{5}$.

As lesões traumáticas nos tecidos moles são classificadas em: contusão, abrasão e laceração, que podem ocorrer no meio intraoral ou extraoral. A contusão é caracterizada por ser uma injúria mecânica, geralmente, causada por impacto, que resulta em hemorragia e edema sob a pele ou mucosa não lacerada. A abrasão é provocada por grande atrição tecidual e é definida por escoriação ou remoção circunscrita de uma camada superficial da pele ou mucosa (nesse caso, é denominada ulceração). A laceração é uma lesão caracterizada por corte no tecido. A severidade dessas lesões pode estar associada à gravidade dos traumatismos, e a identificação do tipo e da severidade das lesões ajuda a definir o tratamento proposto ${ }^{6}$. Outro fator importante é a

http://dx.doi.org/10.5335/rfo.v21i3.6587

Alunos de graduação em Odontologia da Universidade Federal de Pelotas, UFPel, Pelotas, Brasil.

Mestre, doutora e com pós-doutorado em Odontopediatria pela Universidade Federal de Pelotas, UFPel, Pelotas, Brasil. Professora adjunta em Odontopediatria da Universidade de Brasília, UnB, Brasília, Brasil. 
localização anatômica da lesão, pois o fornecimento de sangue à área lesada interfere no tempo necessário para a cura completa do ferimento. Além disso, essas lesões requerem muita atenção, pois, se não forem devidamente tratadas, podem causar defeitos estéticos e funcionais, afetando o psicológico do indivíduo ${ }^{4}$.

A etiologia das lesões traumáticas na dentição decídua e, consequentemente, das injúrias dos tecidos moles é muito variada. No entanto, até os 5 anos de idade, as quedas da própria altura aparecem como as mais comuns, sendo que nessa faixa etária os acidentes domésticos são corriqueiros ${ }^{6}$. À medida que a criança adquire novas habilidades, surgem novas e diferentes situações de risco, que variam entre queimaduras orais por traumatismo elétrico, mordeduras de animais e acidentes ciclísti$\cos ^{6}$, além dos maus-tratos, que também são causa de traumatismo ${ }^{7}$.

O local de ocorrência dessas lesões pode também estar relacionado à idade das crianças. Segundo Soares et al. ${ }^{4}$ (2016), a faixa etária de 0-3 apresenta mais lesões intraorais $(38,9 \%)$ do que extraorais (19,8\%). Quanto à avaliação do tipo e da localização do ferimento, a região extraoral foi mais acometida por contusão (20,7\%) e abrasão (19,3\%), sendo essas mais comuns no lábio superior e a laceração no lábio inferior $(18,4 \%)$. Na região intraoral, a laceração é a lesão que mais ocorre na gengiva (41\%), enquanto os lábios foram mais afetados por abrasão $(12,2 \%)$ e laceração $(24,9 \%)^{4}$. O local onde os dados são coletados também pode interferir na prevalência das injúrias em tecidos moles. Por se tratar de lesões que se regeneram facilmente, são pouco relatadas em estudos de base populacional, sendo, portanto, mais encontradas em estudos referentes a dados de serviços, para onde as injúrias mais severas são encaminhadas $^{5,8}$.

Devido à significativa ocorrência de injúrias em tecidos moles na população infantil e a pouca exploração do tema na literatura, se faz necessário ter conhecimento dos fatores que estão relacionados a essas injúrias. Assim, o objetivo deste estudo retrospectivo é avaliar a prevalência de lesões de tecidos moles em crianças que sofreram traumatismo alveolodentário e que foram atendidas no Núcleo de Estudos e Tratamento dos Traumatismos Alveolodentários na Dentição Decídua (Netrad).

\section{Métodos}

\section{População-alvo}

O presente estudo retrospectivo foi baseado na coleta de dados clínicos de todos os pacientes que procuraram o Netrad para o tratamento de traumatismos alveolodentários em dentes decíduos e de injúrias em tecidos moles. Esse serviço, ligado à Unidade de Clínica Infantil da Faculdade de Odon- tologia da Universidade Federal de Pelotas, promove tratamento para crianças que sofreram traumatismos em dentes decíduos, acompanhando-as até a irrupção dos dentes permanentes correspondentes.

Os pacientes são encaminhados até o serviço por dentistas particulares, unidades básicas de saúde da cidade de Pelotas e região e também pelos residentes em Cirurgia Bucomaxilofacial da mesma faculdade, que realizam serviço de emergência no Pronto-Socorro Municipal. Pelotas é uma cidade localizada no sul do estado do Rio Grande do Sul, considerada polo regional de saúde, e apresenta, aproximadamente, 328.000 habitantes, localizada a $300 \mathrm{~km}$ da capital, Porto Alegre.

Depois de os pais ou responsáveis assinarem o termo de consentimento livre e esclarecido e responderem questões sobre a história médica e sobre onde, quando e como o traumatismo aconteceu, o exame clínico e radiográfico é realizado, juntamente com o registro fotográfico, para compor o prontuário do paciente. No Netrad, os exames clínicos e radiográficos são realizados por estudantes de graduação previamente treinados e constantemente supervisionados por professores da Clínica Infantil.

\section{Coleta de dados}

Os dados dos prontuários dos pacientes atendidos no Netrad de 2002 a 2011 foram coletados por uma única pesquisadora previamente treinada. As informações coletadas foram: idade (em meses), sexo (feminino e masculino), injúria em tecidos moles (classificação de acordo com os critérios descritos por Andreasen e Andreasen ${ }^{9}$ (2001): 1 = contusão; 2 = abrasão; 3 = laceração; intra ou extraoral). A severidade do traumatismo foi classificada em leve, moderada e severa, de acordo com o tipo de traumatismo e seguindo os critérios propostos por Oikarinen e Kassila ${ }^{10}$ (1987), descritos a seguir: injúrias leves - concussão, subluxação, fratura de esmalte e fratura de esmalte-dentina; injúrias moderadas - luxação lateral, extrusão e fratura de esmalte, dentina e polpa; injúrias severas - avulsão, intrusão, fratura coronorradicular e fratura radicular. Quando uma mesma criança apresentou dois ou mais tipos de traumatismo, a injúria mais severa foi considerada.

Os critérios de exclusão utilizados foram: prontuários com ausência de assinatura do termo de consentimento livre e esclarecido ou com ausência de informações relevantes, traumatismo na dentição permanente e não ocorrência de traumatismo (ex.: fratura ocasionada por cárie).

\section{Análise estatística}

Os dados coletados no estudo foram duplamente digitados no programa estatístico EpiInfo 6.04, para avaliar a concordância da digitação. A análise estatística foi realizada utilizando o programa Sta- 
ta 11.0 (Stata Corp. College Station, LP, TX, EUA), incluindo estatística descritiva, distribuição de frequências e tabulações. A significância estatística por associação foi determinada usando o Teste Qui-Quadrado, com nível de significância de 5\%.

\section{Considerações éticas}

O estudo foi aprovado pelo Comitê de Ética em Pesquisa da Universidade Federal de Pelotas (Protocolo 187/2011). Os pais ou responsáveis assinaram o termo de consentimento livre e esclarecido antes do primeiro atendimento e autorizaram a utilização dos dados para futuras pesquisas. Os pacientes são acompanhados periodicamente, levando em consideração a severidade e o tipo de traumatismo, seguindo as recomendações da Associação Internacional de Trauma Dentário (IADT) ${ }^{11}$, até a completa irrupção dos dentes permanentes sucessores.

\section{Resultados}

Dos 707 prontuários de crianças que foram atendidas durante o período do estudo, 104 prontuários foram excluídos, 51 por ter documentação incompleta, 47 por ter outros diagnósticos que não traumatismo e 6 por apresentar traumatismo em dentes permanentes. Vinte e sete crianças apresentaram apenas lesões em tecidos moles.

A Tabela 1 demonstra a caracterização da população do estudo. É possível observar que $51,41 \%$ das crianças que sofreram traumatismo alveolodentário apresentaram lesões em tecidos moles. A maior prevalência de lesões em tecidos moles foi em crianças de 25 a 36 meses $(24,71 \%)$ e entre o sexo masculino $(58,87 \%)$.

Tabela 1 - Descrição da amostra (n=603), Pelotas, Brasil, 2016

\begin{tabular}{lr|r}
\cline { 2 - 3 } & $\mathrm{N}$ & $\%$ \\
\cline { 2 - 3 } Lesões em tecidos moles & 310 & \\
$\quad$ Presente & 248 & 41,41 \\
$\quad$ Ausente & & 48,59 \\
Sexo & 355 & 58,87 \\
$\quad$ Masculino & 248 & 41,13 \\
$\quad$ Feminino & & \\
Idade (meses) & 24 & 3,98 \\
$0-12$ & 114 & 18,91 \\
$13-24$ & 149 & 24,71 \\
$25-36$ & 132 & 21,89 \\
$37-48$ & 95 & 15,75 \\
$49-60$ & 89 & 14,76 \\
$>60$ &
\end{tabular}

A Tabela 2 demonstra a distribuição das lesões em tecidos moles de acordo com o tipo e a localização. A lesão em tecido mole mais prevalente foi a laceração, tanto na região extraoral $(46,75 \%)$ quanto na intraoral $(64,10 \%)$, seguida por contusão e abra- são, respectivamente. Levando em consideração todos os tipos de lesões, a região intraoral foi a mais atingida $(50,32 \%)$.

Tabela 2 - Localização e tipo das lesões em tecidos moles $(n=310)$, Pelotas, Brasil, 2016

\begin{tabular}{|c|c|c|c|c|}
\hline & $\begin{array}{l}\text { Laceração } \\
\text { n }(\%)\end{array}$ & $\begin{array}{c}\text { Abrasão } \\
\text { n } \quad(\%)\end{array}$ & $\begin{array}{c}\text { Contusão } \\
\text { n }(\%)\end{array}$ & $\begin{array}{c}\text { Total } \\
n \quad(\%)\end{array}$ \\
\hline Extraoral & $72(46,75)$ & $44(28,57)$ & $38(24,67)$ & $154(49,68)$ \\
\hline Intraoral & $100(64,10)$ & $6(3,85)$ & $50(32,05)$ & $156(50,32)$ \\
\hline
\end{tabular}

Fonte: dos autores.

Os traumatismos classificados como severos foram os mais frequentes $(43,45 \%)$, seguidos dos leves $(32,17 \%)$ e moderados $(19,90 \%)$. A presença de lesões em tecidos moles foi estatisticamente significante em relação à severidade do traumatismo $(p \leq 0,001)$ e à idade da criança $(p=0,004)$, no entanto, não foi observada diferença em relação ao sexo (Tabela 3).

\begin{tabular}{|c|c|c|c|c|}
\hline & Lesões em te & cidos moles & & \\
\hline & Presente & Ausente & Total & $p$ \\
\hline & $\mathrm{n} \quad(\%)$ & $\mathrm{n} \quad(\%)$ & & \\
\hline Severidade* & & & & $\leq 0,001$ \\
\hline Leve & $83(27,87)$ & $111(37,88)$ & $194(32,17)$ & \\
\hline Moderado & $74(23,87)$ & $46(15,70)$ & $120(19,90)$ & \\
\hline Severo & $128(41,29)$ & $134(45,73)$ & $262(43,45)$ & \\
\hline Sexo & & & & 0,68 \\
\hline Masculino & $185(59,68)$ & $170(58,02)$ & $355(58,87)$ & \\
\hline Feminino & $125(40,32)$ & $123(41,98)$ & $248(41,13)$ & \\
\hline Idade & & & & 0,004 \\
\hline $0-12$ & $16(5,16)$ & $8(2,73)$ & $24(3,98)$ & \\
\hline $13-24$ & $73(23,55)$ & $41(13,99)$ & $114(18,91)$ & \\
\hline $25-36$ & $81(26,13)$ & $68(23,21)$ & $149(24,71)$ & \\
\hline $37-48$ & $62(20,00)$ & $70(23,89)$ & $132(21,89)$ & \\
\hline $49-60$ & $39(12,58)$ & $56(19,11)$ & $95(15,75)$ & \\
\hline$>60$ & $39(12,58)$ & $50(17,06)$ & $89(14,76)$ & \\
\hline
\end{tabular}
Fonte: dos autores.

* $(n=576)$, a severidade só foi estimada para crianças que tiveram traumatismo alveolodentário e 27 apresentaram apenas lesão em tecido mole.

A distribuição dos tipos de lesão em tecido mole de acordo com a idade pode ser observada na Figura 1 , em que crianças de 0-12 meses apresentam mais laceração intraoral $(56,25 \%)$, seguidas das crianças de $37-48$ meses $(35,48 \%)$, quando comparada com as demais lesões. A contusão intraoral foi mais frequente entre crianças de 49-60 meses $(33,33 \%)$, enquanto a laceração extraoral foi mais prevalente em crianças de $37-48$ meses $(32,25 \%)$. A abrasão intraoral foi a menos prevalente em todos os grupos etários, sendo a abrasão extraoral mais prevalente em crianças com mais de 60 meses $(20,51 \%)$. 


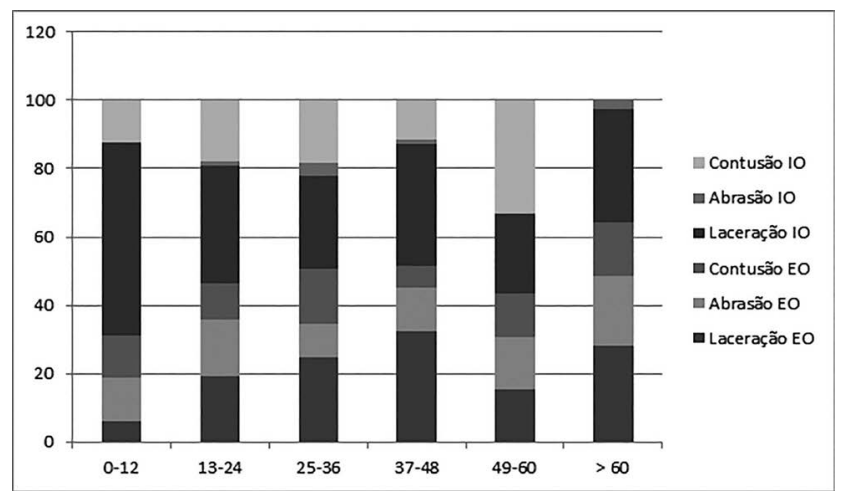

Figura 1 - Distribuição das lesões em tecidos moles de acordo com a idade em meses

Fonte: dos autores.

\section{Discussão}

Os resultados do presente estudo demonstraram que mais de $50 \%$ das crianças que sofreram traumatismo alveolodentário em dentes decíduos apresentaram lesões em tecidos moles. Essa prevalência foi semelhante à encontrada por Soares et al. ${ }^{4}(2016)$ e Vuletić et al. ${ }^{12}$ (2014), 56,2\% e 55,5\%, respectivamente, que também avaliaram crianças e adolescentes atendidos em centros especializados no atendimento de traumatismos em universidades, como no presente estudo. Em centros de emergência ou hospitais, essa prevalência foi um pouco maior, $62,8 \%^{13} 61,68 \%^{14}$ e $58 \%^{15}$.

Eyoboglu et al. ${ }^{16}$ (2009) verificaram uma prevalência de lesões em tecidos moles de $21 \%$. Ela pode ter sido menor, comparada com a maioria dos estudos, inclusive com a prevalência encontrada no presente estudo, porque as crianças, em sua maioria, foram levadas para atendimento três semanas depois da ocorrência do traumatismo, e as lesões em tecidos moles, por cicatrizarem mais rapidamente, podem não ter sido registradas. No entanto, as lesões em tecidos moles, normalmente, envolvem sangramento, o que faz com que a busca por atendimento seja imediata ${ }^{12}$.

As crianças com idades entre 25 e 36 meses apresentaram a maior ocorrência de lesões em tecidos moles, assim como em outros estudos presentes na literatura ${ }^{4,5,12,14,15,17}$. Entretanto, Eyuboglu et al. ${ }^{16}$ (2009) demonstraram que o maior índice de lesões ocorreu por volta dos 5 anos de idade. As lesões na faixa etária de 25 a 36 meses são mais frequentes devido à grande atividade da criança, pois é nesse período que elas aprendem a andar, correr e explorar os ambientes. $\mathrm{O}$ andar já é fixo, entretanto, os reflexos ainda não são bem definidos ${ }^{12}$, o que permite que as quedas sejam corriqueiras, pois uma maior atividade aumenta também o número de brincadeiras e 0 grau de periculosidade dessas ${ }^{15}$. A maior ocorrência de lesões ocorre na idade de 1 a 3 anos, pelo fato de as crianças não possuírem uma coordenação motora totalmente desenvolvida e estarem ganhando mobilidade e independência ${ }^{12,18}$.
A maioria das lesões em tecidos moles aconteceu em meninos, porém, a diferença não foi estatisticamente significativa entre os sexos, assim como em outros estudos ${ }^{4,5,8,14-16}$. A maior prevalência em meninos é resultado da hiperatividade bem como de brincadeiras com um nível de risco maior, o que propicia quedas mais frequentes e acarreta lesões ${ }^{5}$. Os meninos, normalmente, são mais agressivos, aventureiros e participam mais de atividades desportivas ${ }^{19}$. Entretanto, as meninas também podem apresentar uma maior prevalência de injúrias, pois, com idades entre 1 mês a 6 anos, ambos os sexos, estão expostos a fatores de risco muito semelhantes ${ }^{12}$.

No presente estudo, a lesão em tecido mole mais prevalente foi a laceração, tanto na região extraoral $(46,75 \%)$ quanto na intraoral $(64,10 \%)$, seguida por contusão e abrasão, respectivamente. Levando em consideração todos os tipos de lesões, a região intraoral foi a mais atingida (50,32\%), concordando com resultados de outros estudos ${ }^{13-15,20}$.

Crianças muito pequenas apresentam dificuldades de se proteger das quedas de própria altura devido à imaturidade dos níveis de desenvolvimento $\mathrm{e}$ da coordenação motora, o que pode contribuir para o maior número de lacerações. A laceração na língua e nos lábios, comumente, ocorre quando a criança morde essas estruturas no momento em que a mandíbula encontra o chão ou outro objeto durante a queda, sem o adequado apoio dos braços, uma vez que as crianças ainda não desenvolveram esse reflexo ${ }^{15}$.

Como as quedas estão relacionadas às lacerações e são as principais causas de traumatismos alveolodentários, isso pode explicar o fato de a injúria de tecido mole mais prevalente tanto em meninas quanto em meninos ser a laceração $0^{14,16}$. Depois das quedas, as colisões e os acidentes com movimento em meninas e as colisões em esportes em meninos são as causas mais comuns ${ }^{8,15}$. As quedas ocorrem, normalmente, enquanto as crianças estão brincando ou correndo, com ou sem supervisão de adultos ${ }^{14}$. Sandalli et al. ${ }^{8}(2005)$ salientam que fatores de risco como overjet, cobertura labial inadequada e o contexto socioeconômico contribuem para o aumento dos índices de laceração.

Segundo Soares et al. ${ }^{4}$ (2016), na região extraoral, a contusão e a abrasão são mais comuns para o lábio superior, enquanto a laceração para o lábio inferior. Na região intraoral, a lesão mais frequente para lábios e gengiva foi a laceração, devido à sua localização próxima à borda dos incisivos. Uma das limitações do presente estudo foi apenas classificar as lesões em intraoral ou extraoral, sem definir onde essas injúrias ocorreram (ex.: gengiva, lábio, etc.), sendo, portanto, difícil traçar comparações com os estudos que realizam essa classificação.

Os dentes podem, indiretamente, traumatizar os lábios, e a direção do impacto determina a natureza da lesão. Se o impacto é vertical, paralelo ao longo do eixo dos incisivos, a borda incisal pode penetrar em toda a espessura do lábio, causando 
laceração; se a borda incisal atingir o objeto de impacto, também pode ocorrer fratura de coroa, que, normalmente, vem acompanhada de edema nos tecidos moles. Nesse caso, o tecido mole deve ser minuciosamente examinado, verificando se fragmentos dentários não se encontram nesses tecidos, sendo necessárias radiografias para descartar tal possibilidade ${ }^{20}$.

No presente estudo, foi possível verificar que, quanto mais severo foi o traumatismo, maior foi a ocorrência de lesões em tecidos moles. No entanto, não foi possível fazer comparações com outros estudos presentes na literatura, porque poucos estudos abordam a questão da severidade do traumatismo ${ }^{3,10,21} \mathrm{e}$ nenhum faz relação com as lesões em tecidos moles. No entanto, as lesões mais severas envolvem os tecidos de sustentação, que estão associados a lesões em tecidos moles ${ }^{12}$.

Wilson et al..$^{15}$ (1997) verificam que $40 \%$ das lesões em tecidos moles estavam presentes em crianças com menos de 7 anos, o dobro do percentual observado para crianças mais velhas, entre os quais as lacerações foram verificadas em $21 \%$ dos casos de lesões dos tecidos moles. No presente estudo, as lacerações intraorais ocorreram mais em crianças de 0-12 meses, seguidas das crianças de 37-48 meses. A abrasão intraoral foi a menos prevalente em todos os grupos etários, sendo a abrasão extraoral mais prevalente em crianças com mais de 60 meses. Soares et al. ${ }^{4}$ (2016) também identificaram que as lesões intraorais foram mais comuns em crianças de 0-3 anos, comparadas com lesões extraorais.

Normalmente, as lesões em tecidos moles são acompanhadas por injúrias dentárias e, nesse caso, o recomendado é tratar as lesões dentárias primeiro, promovendo uma manipulação mínima nos tecidos moles ${ }^{22}$. No entanto, esses tecidos devem receber a mesma atenção, com inspeção e tratamento adequados para cada situação ${ }^{20}$. É indispensável que se realize a descontaminação da lesão, a verificação da sua origem e extensão, além da avaliação da necessidade de antibiótico, debridamento, limpeza dos ferimentos, reposicionamento e sutura dos tecidos lesados. O tratamento se faz necessário para acelerar o processo de recuperação, evitando infecções e outras possíveis complicações ${ }^{6}$.

\section{Conclusões}

Mais de 50\% dos pacientes que sofrem injúrias dentárias também apresentam lesões em tecidos moles, as quais estão relacionadas com a idade da criança e a severidade do traumatismo. Sendo assim, é necessário ressaltar a importância do exame e do tratamento das lesões em tecidos moles, quando da ocorrência de traumatismos alveolodentários.

\section{Abstract}

Objective: to evaluate the prevalence of soft tissue injuries in children who suffered alveolodental trauma in primary teeth and were assisted at a specialized service of the School of Dentistry of the Federal University of Pelotas, RS, Brazil. Methods: data collected from the medical records of patients treated from 2002 to 2011 included age, gender, soft tissue injury, and severity of dental trauma. Data were analyzed by descriptive statistics and associations were made with the chi-square test, using the Stata 11.0 software. Results: from 707 medical records analyzed, 603 children were included in the study. From this total, 51.41\% presented soft tissue injuries, besides dental injuries. The highest prevalence of soft tissue injuries was for children aged 25 to 36 months $(24.71 \%)$ and for the male gender (58.87\%). The presence of soft tissue injuries was statistically significant in relation to the severity of dental trauma $(p \leq 0.001)$ and the age of children $(p=0.004)$, but there was no difference considering gender. The most prevalent soft tissue injury was laceration, both intraoral (64.10\%) and extraoral (46.75\%), followed by contusion and abrasion. Considering all types of injuries, the intraoral region was mostly affected (50.32\%). Conclusion: soft tissue injuries are present in a great portion of children who suffer trauma (51.41\%), so it is worth noting the importance of examining and treating such injuries.

Keywords: Children. Soft tissue injuries. Prevalence. Dental trauma.

\section{Referências}

1. Nogueira AJS, Melo CB, Faria PJV, Nogueira RGM, Sampaio AMS. Prevalência de traumatismos dos dentes decíduos em crianças da faixa etária de 0 à 5 anos. JBP Rev Ibero-Am Odontopediatr Odontol Bebê 2004;7(37):266-71.

2. Wendt FP, Torriani DD, Assunção MC, Romano AR, Bonow MLM, Costa CT, et al. Traumatic dental injuries in primary dentition: epidemiological study among preschool children in South Brazil. Dent Traumatol 2010;26:168-73.

3. Costa VPP, Bertoldi AD, Baldissera EZ, Goettems ML, Correa MB, Torriani DD. Traumatic dental injuries in primary teeth: severity and related factors observed at a specialist treatment centre in Brazil. Eur Arch Paediatr Dent 2014;15(2):83-8.

4. Soares TRC, Barbosa ACU, Oliveira SNS, Oliveira EM, Risso PA, Maia LC. Prevalence of soft tissue injuries in pediatric patients and its relationship with the quest for treatment. Dent Traumatol 2016;32:48-51.

5. Choi SC, Park JH, Pae A, Kim JR. Retrospective study on traumatic dental injuries in preschool children at Kyung Hee Dental Hospital, Seoul, South Korea. Dent Traumatol 2010; 26:70-5.

6. Kramer PF, Feldens CA. Traumatismo na dentição decíduaprevenção, diagnóstico e tratamento. 2. ed. São Paulo: Santos; 2013. p. 336.

7. Cavalcanti AL, Valença AMG, Duarte RC. O odontopediatra diante de maus tratos Infantis - diagnóstico e conduta. J Bras Odontopediatr Odontol Bebê 2000;3(16):451-5. 
8. Sandalli N, Cildir S, Guler N. Clinical investigation of traumatic injuries in Yeditepe University, Turkey during the last 3 years. Dent Traumatol 2005;21:188-94.

9. Andreasen JO, Andreasen FM. Texto e atlas colorido de traumatismo dental. Porto Alegre: Art Med; 2001. p. 770.

10. Oikarinen K, Kassila O. Causes and types of traumatic tooth injuries treated in a public dental health clinic. Endod Dent Traumatol 1987;3:172-7.

11. Malmgren B, Andreasen JO, Flores MT, Robertson A, DiAngelis AJ, Andersson L, et al. Guidelines for the Management of Traumatic Dental Injuries: 3. Injuries in the Primary Dentition. Pediatr Dent 2016;38(6):377-85.

12. Vuletić M, Škaričić J, Batinjan G, Trampuš Z, Bagić IC, Jurić $\mathrm{H}$. A retrospective study on traumatic dental and softtissue injuries in preschool children in Zagreb, Croatia. Bosn J Basic Med Sci 2014;14(1):12-5.

13. O'Neil DW, Clark MV, Lowe JW, Harrington MS. Oral trauma in children: a hospital survey. Oral Surg Oral Med Oral Pathol 1989;68:691-6.

14. Shayegan A, Maertelaer V, Abbeele AV. The prevalence of traumatic dental injuries: a 24-month Survey. J Dent Child 2007;74:194-9.

15. Wilson S, Smith GA, Preisch J, Casamassimo OS. Epidemiology of dental trauma treated in an urban pediatric emergency department. Pediatr Emerg Care 1997; 13(1):12-5.

16. Eyuboglu O, Zehir YYC, Sahin H. A 6-year investigation into types of dental trauma treated in a paediatric dentistry clinic in Eastern Anatolia Region, Turkey. Dent Traumatol 2009;25:110-4.

17. Andreasen JO, Andreasen FM, Bakland LK, Flores MT. Traumatic dental injuries - a manual. Copenhagen: January 1999.

18. Andreasen JO, Ravn JJ. Epidemiology of traumatic dental injuries to primary and permanent teeth in a Danish population sample. Int J Oral Surg 1972;1(5):235-9.

19. Lombardi S, Sheller B, Williams BJ. Diagnosis and treatment of dental trauma in a children's hospital. Pediatr Dent 1998;20(2):112-20.

20. Al-Jundi SH. The importance of soft tissue examination in traumatic dental injuries: a case report. Dent Traumatol 2010;26:509-11.

21. Skaare AB, Jacobsen I. Primary tooth injuries in Norwegian children (1-8 years). Dent Traumatol 2005;21:315-9.

22. Andreassen JO, Andreassen FM, Andersson L. Textbook and color atlas of traumatic injuries to the teeth. 2007.

Endereço para correspondência:

Vanessa Polina Pereira Costa

UnB - Campus Darcy Ribeiro

70910-900 - Asa Norte, Brasília - DF

Fone: (61) 998635968

E-mail: polinatur@yahoo.com.br

Recebido: 12 / 12 /2016. Aceito: 20/03/2017. 